\title{
Androgen Receptor Coregulator Long Non Coding RNA CTBP1-AS Is Associated With Polycystic Ovary Syndrome in Kashmiri Women
}

Shajrul Amin ( $\square$ shajrulamin@uok.edu.in )

University of Kashmir https://orcid.org/0000-0002-1631-3429

Mudasar Nabi

University of Kashmir

Syed Mudasir Andrabi

SKUAST FVSc and AH: Sher-E-Kashmir University of Agricultural Sciences and Technology Faculty of

Veterinary Sciences and Animal Husbandry

Shayaq UI Abeer Rasool

University of Kashmir

Sairish Ashraf

University of Kashmir

Imarn Majid

Cutis Institute of Dermatology

\section{Research Article}

Keywords: Hyperandrogenism, Hirsutism, CTBP1-AS and polycystic ovaries

Posted Date: June 22nd, 2021

DOI: https://doi.org/10.21203/rs.3.rs-633719/v1

License: (c) (1) This work is licensed under a Creative Commons Attribution 4.0 International License.

Read Full License 


\section{Abstract}

Objective: Polycystic ovary syndrome (PCOS) is one of the most common reproductive, endocrine and metabolic disorders in premenopausal women. Even though the pathophysiology of PCOS is complex and obscure, the disorder is prominently considered as the syndrome of hyperandrogenism. C-Terminal binding protein 1 antisense (CTBP1-AS) acts as a novel Androgen Receptor regulating long noncoding RNA (IncRNA). Therefore, the present study was aimed to establish the possible association of androgen receptor regulating long noncoding RNA CTBP1-AS with PCOS.

Methods: A total of 178 subjects including 105 PCOS cases and 73 age-matched healthy controls were recruited for the study. The anthropometric, hormonal and biochemical parameters of all subjects were analysed. Total RNA was isolated from peripheral venous blood and expression analysis was done by quantitative real time PCR (qRT-PCR). The correlation analysis was performed to evaluate the association between and various clinical parameters and IncRNA CTBP1-AS expression.

Results and conclusion: the mean expression level of CTBP1-AS was found to be significantly higher in the PCOS women than in the healthy controls (-InCTBP1-AS, $4.23 \pm 1.68$ versus $1.24 \pm 0.29 p<0.001$ ). Further, subjects with higher expression level of CTBP1-AS had significantly higher risk of PCOS compared to subjects with low levels of CTBP1-AS expression (actual OR $=11.36,95 \%$ C.I. $=5.59-23.08, \mathrm{P}$ $=<0.001$ ). The area under ROC curve (AUC) was 0.987 (SE 0.006 and 95\% C.I. 0.976-0.99). However, IncRNA CTBP1-AS was found to have no association with different clinical characteristics in PCOS. In conclusion, androgen receptor coregulating IncRNA CTBP1-AS is associated with PCOS women and high expression of CTBP1-AS is a risk factor for PCOS in Kashmiri women

\section{Introduction}

Polycystic ovary syndrome (PCOS) is considered one of the most common reproductive, endocrine and metabolic disorders affecting approximately $10 \%$ of premenopausal women. PCOS affects approximately $10 \%$ of women worldwide ${ }^{1}$. It is a heterogeneous disorder and comes with a wide spectrum of clinical manifestations that include endocrine, metabolic, reproductive and sometimes psychological anomalies. Even though the pathophysiology of PCOS is complex and obscure, the disorder is prominently considered as the syndrome of hyperandrogenism ${ }^{2}$. Hyperandrogenism can either be attributed to excessive serum testosterone levels or hyperactivity of the androgen receptor. The transcriptional activity of AR is regulated by a number of coregulators ${ }^{3}$. Consequently, any abnormal activity of these androgen receptor modulators either due to altered expression or by any mutation may lead to impaired activity of androgen receptor and thereby play a role in the pathogenesis of hyperandrogenism and PCOS.

The recent advancements in genome sequencing technologies revealed that the major portion of the genome is transcriptionally active and encodes for noncoding RNAs ${ }^{4}$. Long Non Coding RNAs (IncRNAs) are the noncoding RNA transcripts of more than 200 nucleotide length, they constitute a significant 
proportion of noncoding RNAs ${ }^{5}$. A number of studies have demonstrated their role in a wide variety of biological processes ${ }^{6,7}$. However, the mechanism of action is yet poorly understood. Primarily they act as epigenetic modulators, regulating gene expression at the transcriptional level as well as at posttranscriptional level. Besides dysregulation of IncRNAs has been implicated in various diseases ${ }^{8}$

long non coding RNA C-terminal binding protein 1 antisense (CTBP1-AS) is associated with androgen receptor signalling pathway, acting as AR modulator. CTBP1-AS is located in the antisense region of Cterminal binding protein 1 (CTBP1), which acts by regulating the expression of AR corepressor $\mathrm{C}$-terminal binding protein 1. LncRNA CTBP1-AS acts by repressing the transcription of CTBP1. CTBP1-AS first associates with transcriptional repressor Polypyrimidine Tract Binding Protein associated splicing factor (PSF) and then recruits histone deacetylases-paired amphipathic helix protein Sin3A complexes on to the promoter region of the gene. Thus CTBP1-AS downregulates transcription of CTBP, thereby promoting the transcriptional activity of AR. In addition to this CTBP1-AS itself mimics androgen receptor signalling by inducing upregulation of the androgen receptor regulated genes ${ }^{9}$.

The aim of this study was to evaluate the association of androgen receptor coregulator IncRNA CTBP1AS with the risk of PCOS in ethnic Kashmiri women. We also attempted to find the correlation of IncRNA CTBP1-AS expression with various clinical manifestations of PCOS.

\section{Materials And Methods}

\section{Recruitment of Subjects}

In this case-control study, a total of 178 subjects were recruited of which 105 were drug naïve PCOS women and 73 were age-matched healthy controls. PCOS cases were recruited from the patients attending OPD of Department of Endocrinology, Sher-e-Kashmir Institute of Medical Sciences (SKIMS), Srinagar, Jammu and Kashmir, India and Department of Obstetrics and Gynaecology, Govt. Medical College, Srinagar, Jammu and Kashmir, India for PCOS related complications from October 2017 to March 2020. The inclusion criteria for PCOS patients was based on the Rotterdam criteria ${ }^{10}$. All those subjects who presented with PCOS mimicking disorders including thyroid dysfunction , hyperprolactinemia , congenital adrenal hyperplasia, androgen secreting tumours and Cushing's syndrome were excluded from the study. Controls recruited for the study were age matched healthy women with regular cycles, no signs of hyperandrogenism clinical/ biochemical, with no history of autoimmune or endocrine disorders. All of the subjects were ethnic Kashmiris living in Kashmir province

\section{Ethics statement}

This study was approved by the ethical committee Government Medical College Srinagar under ethical approval no. 94/ETH/GMC/ICMR. All subjects were recruited after written informed consent was obtained from them. 
All the subjects underwent general anthropometric measurements that include height, weight, waist, hip, waist-hip ratio (WHR), body mass index (BMI) and FG score. A detailed history of clinical symptoms like menstrual cycles, hirsutism, acne, alopecia, and acanthosis nigricans was also taken from all study subjects. Height was measured using a height measuring scale in standing position without shoes and weight was measured using a weighing scale with light clothing. For measurement of waist circumference, minimum value between the iliac crest and the lateral costal margin was determined in a standing position, and hip circumference was measured as the maximum value over the buttocks. WHR was calculated by dividing waist circumference by the hip circumference. BMI was calculated as weight $(\mathrm{kg}) /$ Height $\left(\mathrm{m}^{2}\right)$. Hirsutism was measured by Ferriman-Gallwey scoring system and a score of greater than 8 was taken as significant. All the PCOS women underwent transabdominal ultrasonography (USG) to measure the number of small peripheral cysts and/or increased ovarian volume.

\section{Hormonal and Biochemical assessment}

For hormonal and biochemical assessment, blood sample was collected in clot activator vials from all the participants after an overnight fast on $2^{\text {nd }}-3$ rd day of their menstrual cycle. The hormonal profile included Testosterone, luteinizing hormone, Follicle stimulating hormone. Thyroid stimulating hormone to exclude thyroid disorders, Prolactin to exclude hyperprolactinemia were estimated by Radioimmunoassay (RIA) using RIA kits (Immunotech S.R.O, Prague, Czech Republic) on Beckman coulter UniCelDxI 800 (Access Immunoassay system). Enzyme-linked immunosorbent assays were used to measure Sex Hormone-Binding Globulin (SHBG), androstenedione, dehydroepiandrosterone sulfate (DHEAS), and fasting insulin using Calbiotech, CA USA and DGR Instruments GmbH Marburg ELISA kits using Skanlt RE 4.0 software on Thermo Scientific Multiskan FC ELISA reader. The biochemical parameters done included oral glucose tolerance test, cholesterol, triglyceride, High Density Lipoprotein cholesterol levels, LowDensity Lipoprotein cholesterol levels, Urea, Creatinine, SGOT, SGPT. All the biochemical parameters were measured on semi-automatic analyzer (ERBA Chemtouch 7, Biochemistry Analyzer, Wiesbaden, Germany) using ERBA bioassay diagnostic kits.

The free androgen index (FAl) was derived using the formula:

$F A I=\frac{\text { Total } \text { Testosterone }}{\text { SHBG }} \times 100$.

Insulin resistance was calculated

"HOMA IR = fasting glucose $(\mathrm{mg} / \mathrm{dL}) \times$ Fasting Insulin $(\mathrm{IU} / \mathrm{L}) / 405 "$.

Quantitative Insulin Sensitivity Check Index (QUICKI) was calculated by formula:

QUICKI $=1 / \log ($ Fasting Insulinu $U / m L+\log ($ fasting glucose $m g / d L)$

Peripheral blood mononuclear cell isolation 
For isolation of peripheral blood mononuclear cell $2 \mathrm{ml}$ blood sample in Na-EDTA vials was obtained from all the subjects. Blood samples were diluted by addition of equal volume of phosphate buffer saline (PBS) followed by density gradient centrifugation using Ficoll-Paque plus (GE Healthcare Bio-Sciences Sweden). After density gradient centrifugation Peripheral blood mononuclear cell (PBMNCs) were isolated and washed twice with PBS to remove any contamination of Ficoll and plasma. The cells thus obtained were stored at $-80^{\circ} \mathrm{C}$ for further processing.

\section{RNA isolation and CDNA Synthesis}

Total RNA was isolated from blood leukocytes by TRIzol method ${ }^{11}$. All of the RNA samples were subjected to DNase treatment using Sigma Aldrich DNase treatment kit according to manufacturer's protocol in order to eliminate any traces of genomic DNA. The RNA thus obtained was checked for integrity on $2 \%$ agarose gel. Qualitative and quantitative analysis of all the RNA samples was done on NanoDrop (Thermo Scientific). All RNA samples with an absorbance $A_{260 / 280}$ ratio of 1.9-2.0 were subsequently used for cDNA synthesis by RT-PCR. $1.5 \mathrm{mg}$ of total RNA was reverse transcribed into cDNA using Thermo Scientific RevertAid First Strand cDNA Synthesis Kit as per manufacturer's protocol in applied biosystems thermal cycler.

\section{Quantitative real-time polymerase chain reaction}

Expression levels of IncRNA CTBP1-AS were measured by Quantitative real-time polymerase chain reaction (qRT-PCR) using $10 \mathrm{ml} \mathrm{KAPA} \mathrm{SYBR}{ }^{\circledR}$ FAST SYBR green , $0.3 \mathrm{ml}$ of forward and $0.3 \mathrm{ml}$ of reverse primers and cDNA less than $100 \mathrm{ng}(1 \mathrm{ml})$ in a $20 \mathrm{ml}$ reaction following manufacturer's protocol. qRT-PCR was performed in Roche LightCycler ${ }^{\circledR} 480$ Instrument II 96 well plate having following reaction protocol pre-incubation at $95^{\circ} \mathrm{C}$ for 5 mins, amplification for 40 cycles at $95^{\circ} \mathrm{C}$ for $20 \mathrm{sec}, 62^{\circ} \mathrm{C}$ for $15 \mathrm{sec}$ and $72^{\circ} \mathrm{C}$ for $15 \mathrm{sec}$. Amplification was followed by melting curve analysis with following conditions $95^{\circ} \mathrm{C}$ for $5 \mathrm{sec}$, $60^{\circ} \mathrm{C}$ for $1 \mathrm{~min}$ and $95^{\circ} \mathrm{C}$ continuous. The amplified product was subsequently run on $2 \%$ agarose gel to confirm product size. The relative expression of CTBP1-AS was estimated by Livak method and BetaActin was used as reference gene ${ }^{12}$. Each reaction of qRT-PCR was performed in triplicates.

The following primers were used to quantify the IncRNA CTBP1-AS levels: $5^{\prime}$ -

TTGATGAGGTGGTGGTTGTG -3' (forward) and 5' - GACCCTTACTTGTCGGATGG - 3 ' (reverse), $\beta$-Actin RNA was quantified as a control to normalize differences in total RNA levels using the following primers 5 '- ATCGGAACGGTGAAGGTGACA -3' (forward) and 5'- ATGGCAAGGGACTTCCTGTAAC -3' (reverse).

\section{Statistical Analysis}

All baseline quantitative variables were expressed as mean \pm SD. The anthropometric, hormonal and biochemical parametric variables between PCOS and controls and were compared by unpaired student ttest. Chi square test was used to study association of CTBP1-AS expression and various non-parametric variables. The relation between different metabolic and endocrine markers with CTBP1-AS was evaluated by Pearson or Spearman rank correlation coefficient. The expression of CTBP1-AS was divided into 
binary groups in both PCOS cases and in healthy controls based on limits derived from the healthy control group as follows $<1.81$ for the low expression and $>1.81$ for high expression. Receiver operator characteristic (ROC) and area under curve (AUC) was calculated using Sigma Plot 10. The statistical analysis was done using statistical computing tool vassarstats (http://vassarstats.net/). P-value of $<0.05$ was considered as statistically significant.

\section{Results}

\section{Clinical Characteristics of subjects}

The Clinical, hormonal and metabolic characteristics PCOS patients $(n=105)$ and controls $(n=73)$ are summarized in Table 1. The baseline characteristics of controls and PCOS patients like age, menarche, and height were comparable with no statistically significant difference. However, weight, BMI, Waist-Hip ratio (WHR), FG score, was significantly higher in PCOS patients compared to controls.

Various hormones like total Testosterone ( $59.25 \pm 21.40$ vs $25.99 \pm 8.78, P<0.001)$, androstenedione $(3.40 \pm 0.83$ vs $2.71 \pm 0.64,<0.001)$ DHEA-S $(3.76 \pm 1.17$ vs $3.16 \pm 1.23, P 0.001)$, fasting insulin $(17.31 \pm$ 5.37 vs $6.24 \pm 3.66<0.001)$, LH $(9.76 \pm 4.89$ Vs $6.18 \pm 1.64<0.001)$ were significantly higher in PCOS women than controls. While the levels of FSH $(6.21 \pm 1.55$ vs $7.103 \pm 1.61,0.002)$ and SHBG $(44.59 \pm$ 13.66 vs $61.39 \pm 20.87<0.001)$ where significantly lower in PCOS cases compared to controls. Details are summarized in table 1.

\section{Expression of IncRNA CTBP1-AS in PCOS women and controls}

Shown in Fig. 1, the mean expression level of CTBP1-AS in peripheral blood leukocytes was significantly higher in the PCOS women than that in the healthy controls (-InCTBP1-AS, $4.23 \pm 1.68$ versus $1.24 \pm 0.29$ $p<0.001)$.

\section{Association Between Expression of IncRNA CTBP1-AS and Presence of PCOS}

Further, we sought to evaluate the relationship between different expression levels of CTBP1-AS and risk of PCOS. The subjects were divided into binary groups of high and low expression based on restrictions set by control group. As shown in Table 2, subjects with higher expression level of CTBP1-AS had significantly higher risk of PCOS compared to subjects with low levels of CTBP1-AS expression.

\section{Receiver operator characteristic of IncRNA CTBP1-AS Expression between PCOS cases and healthy controls}

Receiver operator characteristic (ROC) curve analysis was performed with the healthy controls as a reference, the area under the curve (AUC) was 0.987 , with a standard error of 0.006 and $95 \%$ confidence interval of $0.976-0.99$ (Fig. 2).

\section{Correlation Between IncRNA CTBP1-AS Level and Clinical Parameters in PCOS}


Correlation between CTBP1-AS expression level and various clinical parameters in PCOS cases and in controls was done by calculating Pearson or Spearman rank correlation. The expression of IncRNA CTBP1-AS was used as dependent variable, and clinical parameters both in PCOS cases and in controls as independent variables. As shown in Table 3, no association was found between expression of IncRNA CTBP1-AS and any of the biochemical characteristics .

\section{Association between IncRNA CTBP1-AS expression and Hirsutism}

We sought to evaluate the association between expression levels of CTBP1-AS and clinical hyperandrogenic trait, hirsutism in PCOS women. The PCOS cases were divided into binary groups based on presence and absence of hirsutism and expression levels were compared by T-test. As shown in Table 4 no significant association was found between expression of CTBP1-AS and hirsutism $(P=0.64)$

\section{Association of CTBP1-AS Expression with total testosterone}

To explore the association of IncRNA CTBP1-AS expression with total testosterone (TT). The PCOS subjects were grouped into high TT $(>50 \mathrm{ng} / \mathrm{dl})$ and low TT $(<50 \mathrm{ng} / \mathrm{dl})$ group and T-test was used to compare the expression levels. No significant association was found between the expression of CTBP1AS and total testosterone $(P=0.93)$ (Table 5).

\section{Association between IncRNA CTBP1-AS expression obesity}

Association between expression of IncRNA CTBP1-AS and obesity was evaluated by T-test. The subjects were categorised into two groups those having $B M l<25 \mathrm{~kg} / \mathrm{m}^{2}$ and those having $B M l>25 \mathrm{~kg} / \mathrm{m}^{2}$. As shown in table 6, no significant difference in the expression of CTBP1-AS was found between two groups in both cases $(P=0.897)$ and controls $(P=0.154)$.

\section{Discussion}

This study is first of its kind that investigated the association of IncRNAs CTBP1-AS with the risk of PCOS and its clinical manifestation in North Indian PCOS women. Androgen receptor (AR) regulating IncRNA CTBP1-AS was significantly overexpressed in PCOS women than in healthy controls. We also found that high expression CTBP1-AS as a risk factor for PCOS but has not a significant role in driving various clinical manifestations associated with PCOS.

PCOS is a multisystemic disorder associated with varied immediate complications like hirsutism, acne, alopecia, menstrual irregularities and a range of long term metabolic, cardiovascular, and psychological complications ${ }^{13,14}$. Previous studies have shown that PCOS women are predisposed to obesity ${ }^{15-18}$. Our study showed similar results, BMI $(P<.001)$, WHR $(P<.001)$ were significantly higher in women with PCOS than in healthy women. Studies have shown PCOS women have abnormal metabolic, hormonal parameters ${ }^{15-20}$. Consistently, in our study various metabolic parameters were found deranged in PCOS women. Insulin resistance marker HOMA IR $(P<.001)$ was significantly higher in PCOS women compared 
to healthy females and insulin sensitivity was also found significantly lower in PCOS than in controls; QUICKI $(P<.001)$. Women with PCOS are predisposed to high risk liver disease and have elevated levels of liver enzymes ${ }^{21,22}$. Similar results were demonstrated in our study, liver enzymes AST $(P<.001)$, ALT $(P<.001)$ were significantly higher in PCOS women than in controls.

The etiology of PCOS is still obscure nevertheless, hyperandrogenism is the cardinal feature of PCOS which plays a central development of PCOS ${ }^{23}$. The primary complaints of PCOS like hirsutism, alopecia, Acne, polycystic ovaries, menstrual irregularities are the outcomes of hyperandrogenism ${ }^{23-25}$. Hyperandrogenic effect is either due to high levels of serum testosterone or hyperactivity of androgen receptor. The activity of the androgen receptor is regulated by different coactivators and corepressors ${ }^{3,26}$. Studies have shown hyperactive AR at ovarian and extraovarian sites including hypothalamus, skeletal muscles, and adipocytes play a crucial role in PCOS pathophysiology. The amplified androgenic response via hyperactivity of androgen receptor especially at neuroendocrine site promotes abnormal GnRH pulsation, early follicular development, subsequently follicular arrest, ovulatory dysfunction and other hyperandrogenic manifestations associated with PCOS $23,27,28$. Thus, androgen receptor, its downstream signalling molecules together with coregulators are critical elements for understanding the mechanism of progression of PCOS, its clinical manifestations and development of novel AR based therapeutic treatments.

LncRNAs have a tremendous role in normal cellular processes and development ${ }^{29-31}$. LncRNAs act as regulators of gene expression, post-transcriptionally they can act as regulators by regulating splicing, translation, stability of proteins and mRNA decay etc ${ }^{32}$. Consequently, they assume important role in disease pathogenesis and progression. Studies have shown that dysregulation of IncRNAs are involved in various disorders like cancer, metabolic diseases and other endocrine-related disorders such as diabetes mellitus. Studies have revealed that IncRNAs have been involved in the development and regulation of the female reproductive system moreover, they play a crucial role in the pathogenesis of various gynaecological-related diseases like endometriosis and various gynaecological cancers such as cervical, endometrial, and ovarian cancers ${ }^{33}$.

C-Terminal binding protein 1 (CTBP1) is one of the androgen receptor coregulator which plays an important role in androgen signalling by acting as a corepressor of AR thereby decreasing the androgenic effect. The CTBP1 corepressor is in turn regulated by its antisense IncRNA CTBP1-AS. This IncRNA is extensively studied in AR signalling cascade. The role of CTBP1-AS as novel positive regulator of AR transcriptional activity was confirmed by Takayama and co-workers. They showed that CTBP1-AS acts by promoting the repression of CTBP1 protein and it also the releases repressors of AR-regulated genes from their regulatory regions. Thus CTBP1-AS IncRNA promotes hyperactive androgen response and subsequent transcriptional activation of genes regulated by the androgen ${ }^{9}$. In present study, we showed CTBP1-AS is significantly overexpressed $(P<.001)$ in PCOS women compared to controls. Further, we also found women with higher expression of CTBP1-AS are at greater risk of developing PCOS than women with lower CTBP1-AS expression. Similar results were reported by Liu et.al, who investigated 23 
PCOS women and 17 controls of Chinese ethnicity and found significantly higher CTBP1-AS expression in PCOS women ${ }^{34}$. Taken together these studies suggest CTBP1-AS as an important factor for hyperactivity of AR and development of androgenic disorders like PCOS.

The clinical manifestations of PCOS are varied and complex. Primary clinical manifestations like hirsutism acne alopecia menstrual irregularity are outcomes of multiple biological interactions which may require simultaneous presence of various genetic, epigenetic and environmental factors ${ }^{35-40}$. Although, in present study we showed CTBP1-AS is associated with PCOS. However, we didn't find any correlation between CTBP1-AS expression and various clinical manifestations of PCOS. Hirsutism $(P=$ $0.74207)$ Acne $(P=0.74207)$ Alopecia $(P=0.689985)$ were not significantly associated with expression of CTBP1-AS. Our study is consistent with previous study by carried out by Liu et.al, on Chinese women with $\mathrm{PCOS}^{34}$. This may be attributed to the fact that in this complex syndrome, multiple factors come into the play and act together so as to bring about a phenotypic change or a specific clinical manifestation. We assume that CTBP1-AS may be one of these contributing factors that in association with other factors is responsible for development of various clinical manifestations in PCOS. However, further mechanistic insights are needed so as to understand how and to what extent CTBP1-AS influences the different phenotypic features in PCOS.

We further evaluated the correlation of CTBP1-AS expression with different hormonal and biochemical parameters. We didn't find any significant correlation between CTBP1-AS expression and various hormonal or biochemical parameters. Testosterone $(P=0.99)$, Insulin $(P=0.53)$, SHBG $(P=0.67), \mathrm{LH}(P$ $=0.51), \mathrm{FSH}(P=0.72)$, Androandrostenrdione $(P=0.93)$ didn't show significant correlation with CTBP1AS expression. However, contrary to our results, Lui and co-workers found a positive correlation between expression of CTBP1-AS and serum total testosterone $(P=0.027)$ in a small case control study on Chinese women (cases/controls 23/17) ${ }^{34}$. The possible reason for such correlation may be because of small sample size in their study. Furthermore, it is believed that CTBP1-AS affects downstream signalling of androgen by enhancing the transcriptional activity of AR and may not have direct effect on biosynthesis of androgens. However, more elaborated studies need to be carried out to so as to understand the effect of CTBP1-AS on biosynthesis of testosterone.

\section{Conclusion}

In conclusion, our study showed that AR coregulating IncRNA CTBP1-AS is associated with PCOS women and high expression of CTBP1-AS is a risk factor for PCOS in Kashmiri women. Higher expression levels of CTBP1-AS may act as an important factor for hyperactivity of AR and may contribute towards the pathophysiology of PCOS. However, further investigations are needed to understand the mechanism of action of CTBP1-AS and identify signalling pathway. This will help to further understand the role played by IncRNA CTBP1-AS in pathophysiology of PCOS, its clinical manifestations and in identifying therapeutic targets. 


\section{Declarations}

\section{Funding}

This work was supported by the Indian Council of Medical Research under grant No. RBMH/FW/2019/3

\section{Conflict of interest}

On behalf of all the authors, the corresponding author declares that there is no conflict of interest.

\section{Availability of data and materials}

The data and materials will be provided by authors on reasonable request.

\section{Authors' contributions}

M.N.: Major work done, Manuscript Writing, Project Development, Recruitment of Participants, Sample collection, Data Collection,

S.M.A: Primer designing and qPCR validation.

S.U.A: Data Collection, Manuscript Revision.

S.A. : Recruitment of Participants, Manuscript revision, data collection

I.M.: Diagnosis and recruitment of Cases

S.A.: Conception and design, Manuscript writing, Project development and management.

All authors read and approved the final draft.

\section{Ethics approval}

This study was approved by the ethical committee Government Medical College Srinagar under ethical approval no. 94/ETH/GMC/ICMR

\section{Consent of participation}

All participants were recruited after written informed consent was obtained from them.

\section{Consent for publication}

All authors have approved the manuscript for submission.

\section{Acknowledgements}


We thank all the study subjects. We are also thankful to Mr. Suhail Murtaza technical assistant, who assisted in sampling of PCOS cases and control women. We are thankful to Co-scholars for their help during the course of experimental studies.

\section{References}

1. Escobar-Morreale HF. Polycystic ovary syndrome: Definition, aetiology, diagnosis and treatment. Nature Reviews Endocrinology. 2018;14(5):270-284.

2. Azziz R, Carmina E, Dewailly D, et al. Position statement: Criteria for defining polycystic ovary syndrome as a predominantly hyperandrogenic syndrome: An androgen excess society guideline. Journal of Clinical Endocrinology and Metabolism. 2006;91(11):4237-4245.

3. Liu S, Kumari S, Hu Q, et al. A comprehensive analysis of coregulator recruitment, androgen receptor function and gene expression in prostate cancer. eLife. 2017;6:e28482.

4. Djebali S, Davis CA, Merkel A, et al. Landscape of transcription in human cells. Nature. 2012;489(7414):101-108.

5. Liao Q, Xiao H, Bu D, et al. NcFANs: A web server for functional annotation of long non-coding RNAs. Nucleic Acids Research. 2011;39(web server issue):w1118-w1124.

6. Fatica A, Bozzoni I. Long non-coding RNAs: New players in cell differentiation and development. Nature Reviews Genetics. 2014;15(1):7-21.

7. Sun M, Kraus WL. From discovery to function: The expanding roles of long noncoding RNAs in physiology and disease. Endocrine Reviews. 2015;36(1):25-64.

8. Yang X, Gao L, Guo X, et al. A network based method for analysis of IncRNA-disease associations and prediction of IncRNAs implicated in diseases. PLOS ONE. 2014;9(1):e87797.

9. Takayama KI, Horie-Inoue K, Katayama S, et al. Androgen-responsive long noncoding RNA CTBP1-AS promotes prostate cancer. EMBO Journal. 2013;32(12):1665-1680.

10. Fauser BCJM, Tarlatzis, Fauser, et al. Revised 2003 consensus on diagnostic criteria and long-term health risks related to polycystic ovary syndrome. Human Reproduction. 2004;19(1):41-47.

11. Rio DC, Ares M, Hannon GJ, Nilsen TW. Purification of RNA using TRIzol (TRI Reagent). Cold Spring Harbor Protocols. 2010;2010(6):pdb.prot5439.

12. Schmittgen DT, Livak KJ. Analyzing real-time PCR data by the comparative CT method. Nature protocols. 2008;3(6):1101-1108.

13. Anagnostis P, Tarlatzis BC, Kauffman RP. Polycystic ovarian syndrome (PCOS): Long-term metabolic consequences. Metabolism: Clinical and Experimental. 2018;86:33-43.

14. Behboodi Moghadam Z, Fereidooni B, Saffari M, Montazeri A. Measures of health-related quality of life in pcos women: A systematic review. International Journal of Women's Health. 2018;10:397-408.

15. Rasool SUA, Ashraf S, Nabi M, Rashid F, Fazili KM, Amin S. Elevated fasting insulin is associated with cardiovascular and metabolic risk in women with polycystic ovary syndrome. Diabetes and Metabolic Syndrome: Clinical Research and Reviews. 2019;13(0):2098-2105. 
16. Ashraf S, Rasool SUA, Nabi M, et al. CYP17 gene polymorphic sequence variation is associated with hyperandrogenism in Kashmiri women with polycystic ovarian syndrome. Gynecological Endocrinology. 2020;37(3):230-234.

17. Rasool SUA, Ashraf S, Nabi M, et al. Insulin gene VNTR class III allele is a risk factor for insulin resistance in Kashmiri women with polycystic ovary syndrome. Meta Gene. 2019;21(0).

18. Thathapudi S, Kodati V, Erukkambattu J, Katragadda A, Addepally U, Hasan Q. Anthropometric and biochemical characteristics of polycystic ovarian syndrome in south indian women using AES-2006 criteria. International Journal of Endocrinology and Metabolism. 2014;21(1):e12470.

19. Wijeyaratne CN, Seneviratne RDA, Dahanayake S, et al. Phenotype and metabolic profile of South Asian women with polycystic ovary syndrome (PCOS): Results of a large database from a specialist Endocrine Clinic. Human Reproduction. 2011;26(1):202-213.

20. Wang ET, Kao CN, Shinkai K, Pasch L, Cedars MI, Huddleston HG. Phenotypic comparison of Caucasian and Asian women with polycystic ovary syndrome: A cross-sectional study. Fertility and Sterility. 2013;100(1):214-218.

21. Tan S, Bechmann LP, Benson S, et al. Apoptotic markers indicate nonalcoholic steatohepatitis in polycystic ovary syndrome. Journal of Clinical Endocrinology and Metabolism. 2010;95(1):343-348.

22. Minato S, Sakane N, Kotani K, et al. Prevalence and Risk Factors of Elevated Liver Enzymes in Japanese Women With Polycystic Ovary Syndrome. Journal of Clinical Medicine Research. 2018;10(12):904-910.

23. Caldwell ASL, Edwards MC, Desai R, et al. Neuroendocrine androgen action is a key extraovarian mediator in the development of polycystic ovary syndrome. Proceedings of the National Academy of Sciences of the United States of America. 2017;114(16):E3334-E3343.

24. Ashraf S, Nabi M, Rasool S ul A, Rashid F, Amin S. Hyperandrogenism in polycystic ovarian syndrome and role of CYP gene variants: a review. Egyptian Journal of Medical Human Genetics. 2019;20(1):110.

25. Karrer-Voegeli S, Rey F, Reymond MJ, Meuwly JY, Gaillard RC, Gomez F. Androgen dependence of hirsutism, acne, and alopecia in women retrospective analysis of 228 patients investigated for hyperandrogenism. Medicine. 2009;88(01):32-45.

26. Vezza T, Rocha M, Víctor VM. PGK1-AR axis: Benefits of a novel actor in PCOS pathology. EBioMedicine. 2020;62:103110.

27. Walters KA, Handelsman DJ. Role of androgens in the ovary. Molecular and Cellular Endocrinology. 2018;465(0):36-47.

28. Walters KA, Edwards MC, Tesic D, et al. The Role of Central Androgen Receptor Actions in Regulating the Hypothalamic-Pituitary-Ovarian Axis. Neuroendocrinology. 2018;106(4):389-400.

29. Fernandes JCR, Acuña SM, Aoki JI, Floeter-Winter LM, Muxel SM. Long non-coding RNAs in the regulation of gene expression: Physiology and disease. Non-coding RNA. 2019;5(1):17.

30. Iyer MK, Niknafs YS, Malik R, et al. The landscape of long noncoding RNAs in the human transcriptome. Nature Genetics. 2015;47(3):199-208. 
31. Knoll M, Lodish HF, Sun L. Long non-coding RNAs as regulators of the endocrine system. Nature Reviews Endocrinology. 2015;11:151-160.

32. Marchese FP, Raimondi I, Huarte M. The multidimensional mechanisms of long noncoding RNA function. Genome Biology. 2017;18(1):206.

33. Zhao M, Qiu Y, Yang B, et al. Long non-coding RNAs involved in gynecological cancer. International Journal of Gynecological Cancer. 2014;24(7):1140-1145.

34. Liu Z, Hao C, Song D, Zhang N, Bao H, Qu Q. Androgen receptor coregulator CTBP1-AS is associated with polycystic ovary syndrome in Chinese women: A preliminary study. Reproductive Sciences. 2015;22(7):829-837.

35. Escobar-Morreale HF. Reproductive endocrinology: Menstrual dysfunction--a proxy for insulin resistance in PCOS? Nature reviews Endocrinology. 2014;10(1):10-11.

36. Fauser BCJM, Tarlatzis BC, Rebar RW, et al. Consensus on womens health aspects of polycystic ovary syndrome (PCOS). Human Reproduction. 2012;27(1):14-24.

37. Teede H, Deeks A, Moran L. Polycystic ovary syndrome: A complex condition with psychological, reproductive and metabolic manifestations that impacts on health across the lifespan. $B M C$ Medicine. 2010;8:41.

38. Kshetrimayum C, Sharma A, Mishra VV, Kumar S. Polycystic ovarian syndrome: Environmental/ occupational, lifestyle factors; an overview. Journal of the Turkish German Gynecology Association. 2019;20(4):255-263.

39. Archer JS, Chang RJ. Hirsutism and acne in polycystic ovary syndrome. Best Practice and Research: Clinical Obstetrics and Gynaecology. 2004;18(5):737-754.

40. Fatsetti L, Gambera A, Andrico S, Sartori E. Acne and hirsutism in polycystic ovary syndrome: Clinical, endocrine-metabolic and ultrasonographic differences. Gynecological Endocrinology. 2002;16(4):275-284.

\section{Tables}


Table 1

Clinical Characteristic of Controls and Patients With PCOS.

\begin{tabular}{|c|c|c|c|}
\hline Variables & PCOS cases $(n=105)$ & Controls $(n=73)$ & P-Value \\
\hline Age (years) & $23.24 \pm 3.87$ & $24.08 \pm 2.20$ & 0.15 \\
\hline Weight(kg) & $63.91 \pm 9.07$ & $55.06 \pm 5.25$ & $<0.001 *$ \\
\hline Height (cm) & $157.86 \pm 5.42$ & $156.65 \pm 5.36$ & 0.13 \\
\hline $\mathrm{BMI}(\mathrm{kg} / \mathrm{m} 2)$ & $25.63 \pm 3.40$ & $22.43 \pm 1.84$ & $<0.001^{*}$ \\
\hline Waist (cm) & $87.05 \pm 10.22$ & $78.04 \pm 6.62$ & $<0.001^{*}$ \\
\hline Hip (cm) & $94.44 \pm 7.47$ & $90.50 \pm 6.19$ & $0.002^{*}$ \\
\hline WHR & $0.94 \pm 0.076$ & $0.86 \pm 0.059$ & $<0.001^{*}$ \\
\hline Menarche (years) & $13.02 \pm 1.26$ & $13.36 \pm 0.82$ & 0.122 \\
\hline FG Score & $16.34 \pm 5.78$ & $4.23 \pm 2.10$ & $<0.001 *$ \\
\hline LH (IU/L) & $9.76 \pm 4.89$ & $6.18 \pm 1.64$ & $<0.001^{*}$ \\
\hline FSH (IU/L) & $6.21 \pm 1.55$ & $7.10 \pm 1.61$ & $0.002^{*}$ \\
\hline LH: FSH & $1.60 \pm 0.77$ & $0.88 \pm 0.20$ & $<0.001^{*}$ \\
\hline $\mathrm{TT}$ (ng/dL) & $59.25 \pm 21.40$ & $25.99 \pm 8.78$ & $<0.001^{*}$ \\
\hline SHBG (nmol/L) & $44.59 \pm 13.66$ & $61.39 \pm 20.87$ & $<0.001^{*}$ \\
\hline Andro (ng/mL) & $3.40 \pm 0.83$ & $2.71 \pm 0.64$ & $<0.001^{*}$ \\
\hline DHEAS (ng/mL) & $3.76 \pm 1.17$ & $3.16 \pm 1.23$ & $0.001^{*}$ \\
\hline Insulin F ( $\mu \mid \mathrm{l} / \mathrm{ml})$ & $17.31 \pm 5.37$ & $6.24 \pm 3.66$ & $<0.001^{*}$ \\
\hline Glu F (mg/dL) & $89.12 \pm 8.50$ & $84.57 \pm 8.57$ & $0.001^{*}$ \\
\hline Glu $2 \mathrm{~h}(\mathrm{mg} / \mathrm{dL})$ & $125.64 \pm 21.82$ & $105.68 \pm 15.21$ & $<0.001^{*}$ \\
\hline Chol (mg/dL) & $169.72 \pm 29.77$ & $148.13 \pm 20.69$ & $<0.001^{*}$ \\
\hline $\mathrm{TG}(\mathrm{mg} / \mathrm{dL})$ & $128.12 \pm 39.43$ & $104.33 \pm 13.10$ & $<0.001^{*}$ \\
\hline $\mathrm{HDL}(\mathrm{mg} / \mathrm{dL})$ & $43.48 \pm 5.82$ & $47.24 \pm 7.50$ & $<0.001^{*}$ \\
\hline $\mathrm{LDL}(\mathrm{mg} / \mathrm{dL})$ & $104.17 \pm 22.57$ & $95.75 \pm 12.20$ & $0.003^{*}$ \\
\hline Urea (mg/dL) & $24.48 \pm 9.43$ & $21.53 \pm 4.16$ & $0.02^{\star}$ \\
\hline Creatinine $(\mathrm{mg} / \mathrm{dL})$ & $0.88 \pm 0.35$ & $0.76 \pm 0.11$ & $0.006^{*}$ \\
\hline FAI & $4.92 \pm 2.04$ & $1.66 \pm 0.75$ & $<0.001^{*}$ \\
\hline
\end{tabular}




\begin{tabular}{|llll|}
\hline Variables & PCOS cases $(\mathbf{n}=105)$ & Controls $(\mathbf{n}=73)$ & P-Value \\
\hline HOMA-IR & $3.81 \pm 1.27$ & $1.30 \pm 0.78$ & $<0.001$ * \\
\hline QUICKI & $0.31 \pm 0.02$ & $0.39 \pm 0.03$ & $<0.001$ * \\
\hline AST/SGOT U/L & $29.98 \pm 13.88$ & $20.02 \pm 6.30$ & $<0.001$ * \\
\hline ALT/SGPT U/L & $31.23 \pm 17.38$ & $23.03 \pm 5.16$ & $<0.001$ * \\
\hline
\end{tabular}

Data presented as Mean \pm SD. *P-value $<0.05$ significant. P values calculated by Independent Student's ttest.

PCOS; polycystic ovary syndrome, BMI; body mass index, WHR; Waist to hip ratio, FG; Score ferrimangallwey score, $\mathrm{LH}$; luteinizing hormone, $\mathrm{FSH}$; follicle stimulating hormone, TT; total testosterone, SHBG; sex hormone binding globin, Andro; Androandrostenrdione, DHEAS; dihydroepian-

drostenedionesulphate, Glu F; glucose fasting, CHOL; cholesterol, TG; triglycerides, HOMA IR; homeostasis model assessment-estimated insulin resistance, QUICKI; quantitative insulin sensitivity check index, FAl; free androgen index, AST aspartate aminotransferase, ALT alanine aminotransferase

Table 2

Odds Ratio of PCOS Events by Expression of CTBP1-AS.

\begin{tabular}{|llllll|}
\hline $\begin{array}{l}\text { CTBP1-AS } \\
\text { Expression }\end{array}$ & Cases & Controls & Odds ratio & $95 \% \mathrm{Cl}$ & P \\
\cline { 1 - 4 } Low $<1.81$ & $21(20.0 \%)$ & $54(73.97 \%)$ & 11.36 & $5.59-23.08$ & $<0.001^{*}$ \\
\cline { 1 - 4 }$>1.81$ & $84(80.0 \%)$ & $19(26.02 \%)$ & & & \\
\hline
\end{tabular}

Abbreviations: CTBP1-AS; C-terminal binding protein 1 antisense; PCOS, polycystic ovary syndrome; OR, odds ratio; $95 \% \mathrm{Cl}$, confidence intervals. CTBP1-AS expression for binary groups cut offs were $<1.81$ for the low expression, $>1.81$ for the high expression. The $\mathrm{OR}, 95 \% \mathrm{Cl}$, and $\mathrm{P}$ value were estimated for PCOS events in the high expression group compared to the low expression using $X^{2}$ Test. $P$ values $<0.05$ is in bold 
Table 3

Partial Pearson or Spearman Rank Correlation Coefficients of the Expression of CTBP1-AS and Patients' Characteristics

\begin{tabular}{|c|c|c|c|c|}
\hline \multirow[t]{2}{*}{ Parameter } & \multicolumn{2}{|l|}{ CASES } & \multicolumn{2}{|c|}{ CONTROLS } \\
\hline & $r$ & $p$-value & $r$ & p-value \\
\hline BMI & -0.0517 & 0.597253 & 0.0814 & 0.531127 \\
\hline WHR & 0.077 & 0.437180 & -0.2291 & 0.075390 \\
\hline FG score & -0.111 & 0.261101 & 0.1873 & 0.149595 \\
\hline DHEAS & 0.0487 & 0.625176 & -0.1397 & 0.284537 \\
\hline Andro & -0.0079 & 0.936392 & -0.1051 & 0.421195 \\
\hline SHBG & 0.0416 & 0.675360 & 0.1478 & 0.254784 \\
\hline Testo & -0.0006 & 0.992041 & -0.1039 & 0.426920 \\
\hline FAI & 0.006 & 0.952272 & -0.1989 & 0.124108 \\
\hline LH & 0.0645 & 0.510727 & -0.0605 & 0.640088 \\
\hline $\mathrm{FSH}$ & 0.0343 & 0.727053 & 0.0582 & 0.654360 \\
\hline LH:FSH & 0.0379 & 0.697342 & -0.089 & 0.492899 \\
\hline INSULIN & -0.0622 & 0.530097 & -0.0665 & 0.611954 \\
\hline FASTING GLU & 0.1104 & 0.261101 & -0.0237 & 0.857769 \\
\hline $2 \mathrm{HR}$ & 0.0858 & 0.386323 & 0.0797 & 0.544204 \\
\hline $\mathrm{CHOL}$ & 0.0607 & 0.536627 & -0.0424 & 0.742569 \\
\hline TG & 0.007 & 0.944329 & 0.0113 & 0.928592 \\
\hline LDL & -0.0579 & 0.556483 & -0.1085 & 0.404300 \\
\hline HDL & 0.087 & 0.375540 & 0.1123 & 0.387826 \\
\hline HOMA & -0.0194 & 0.841875 & -0.0591 & 0.654360 \\
\hline HIRSUTISM & 0.0326 & 0.74207 & 0.0591 & 0.65436 \\
\hline CYCLES & -0.0643 & 0.517139 & -0.0102 & 0.432692 \\
\hline ACNE & -0.065 & 0.510727 & -0.0043 & 0.976168 \\
\hline ALOPECIA & -0.039 & 0.689985 & -0.0884 & 0.499164 \\
\hline
\end{tabular}

BMl; body mass index, WHR; Waist to hip ratio, FG; Score Ferriman Gallwey score, LH; luteinizing hormone, FSH; follicle stimulating hormone, TT; total testosterone, SHBG; sex hormone binding globin, 
Andro; Androandrostenrdione, DHEAS; dihydroepian-drostenedionesulphate, Glu F; glucose fasting, CHOL; cholesterol, TG; triglycerides, HOMA IR; homeostasis model assessment-estimated insulin resistance, FAl; free androgen index. The correlation coefficient ( $r$ ).

Table 4

Association between expression of IncRNA CTBP1-AS and Hirsutism

\begin{tabular}{|llll|}
\hline Parameter & PCOS & & \\
\hline Hirsutism & Present $(n=93)$ & Absent $(n=12)$ & $p$-value \\
\hline CTBP1-AS Expression (Fold change) & $4.20 \pm 1.65$ & $4.44 \pm 2.03$ & 0.64 \\
\hline
\end{tabular}

Abbreviations: CTBP1-AS; C-terminal binding protein 1 antisense; PCOS, polycystic ovary syndrome

Table 5

Association between expression of IncRNA CTBP1-AS and TT

\begin{tabular}{|llll|}
\hline Parameter & PCOS & & \\
\hline Total Testosterone & $>50 \mathrm{ng} / \mathrm{dl}(\mathrm{n}=69)$ & $<50 \mathrm{ng} / \mathrm{dl}(\mathrm{n}=36)$ & P-value \\
\hline $\begin{array}{l}\text { CTBP1-AS Expression } \\
\text { (Fold change) }\end{array}$ & $4.22 \pm 1.67$ & $4.26 \pm 1.76$ & 0.93 \\
\hline
\end{tabular}

Abbreviations: CTBP1-AS; C-terminal binding protein 1 antisense; PCOS, polycystic ovary syndrome

Table 6

Association between expression of IncRNA CTBP1-AS and obesity

\begin{tabular}{|c|c|c|c|c|c|c|}
\hline Parameter & PCOS & & & controls & & \\
\hline BMI & $\begin{array}{l}\left.<25 \mathrm{~kg} / \mathrm{m}^{2}\right) \\
(\mathrm{n}=52)\end{array}$ & $\begin{array}{l}\left.>25 \mathrm{~kg} / \mathrm{m}^{2}\right) \\
(\mathrm{n}=53)\end{array}$ & $\begin{array}{l}\mathrm{P} \text { - } \\
\text { value }\end{array}$ & $\begin{array}{l}<25 \\
\left.\mathrm{~kg} / \mathrm{m}^{2}\right)(\mathrm{n} \\
=60)\end{array}$ & $\begin{array}{l}>25 \\
\left.\mathrm{~kg} / \mathrm{m}^{2}\right)(\mathrm{n} \\
=13)\end{array}$ & $\begin{array}{l}\mathrm{P} \text { - } \\
\text { value }\end{array}$ \\
\hline $\begin{array}{l}\text { CTBP1-AS Expression } \\
\text { (Fold change) }\end{array}$ & $4.18 \pm 1.81$ & $4.23 \pm 1.56$ & 0.897 & $1.2 \pm 0.67$ & $1.66 \pm 0.80$ & 0.154 \\
\hline
\end{tabular}

Abbreviations: CTBP1-AS; C-terminal binding protein 1 antisense; PCOS, polycystic ovary syndrome BMI; body mass index

\section{Figures}




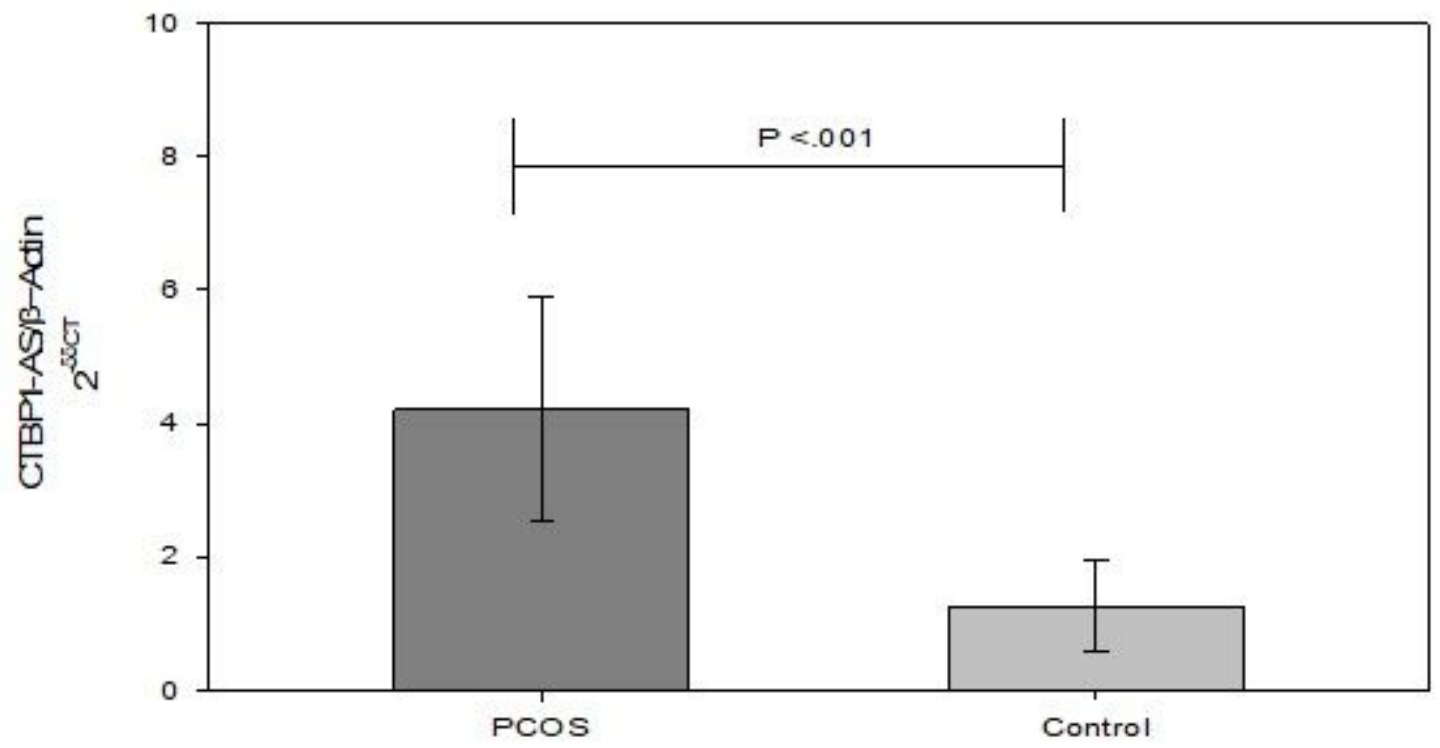

Figure 1

The expression profile of CTBP1-AS in peripheral blood leukocytes in PCOS cases and healthy controls measured by quantitative real- time PCR. Data are expressed as mean $\pm S D * P<0.05$. CTBP1-AS indicates $\mathrm{C}$-terminal binding protein 1 antisense; PCOS, polycystic ovary syndrome

ROC Curve

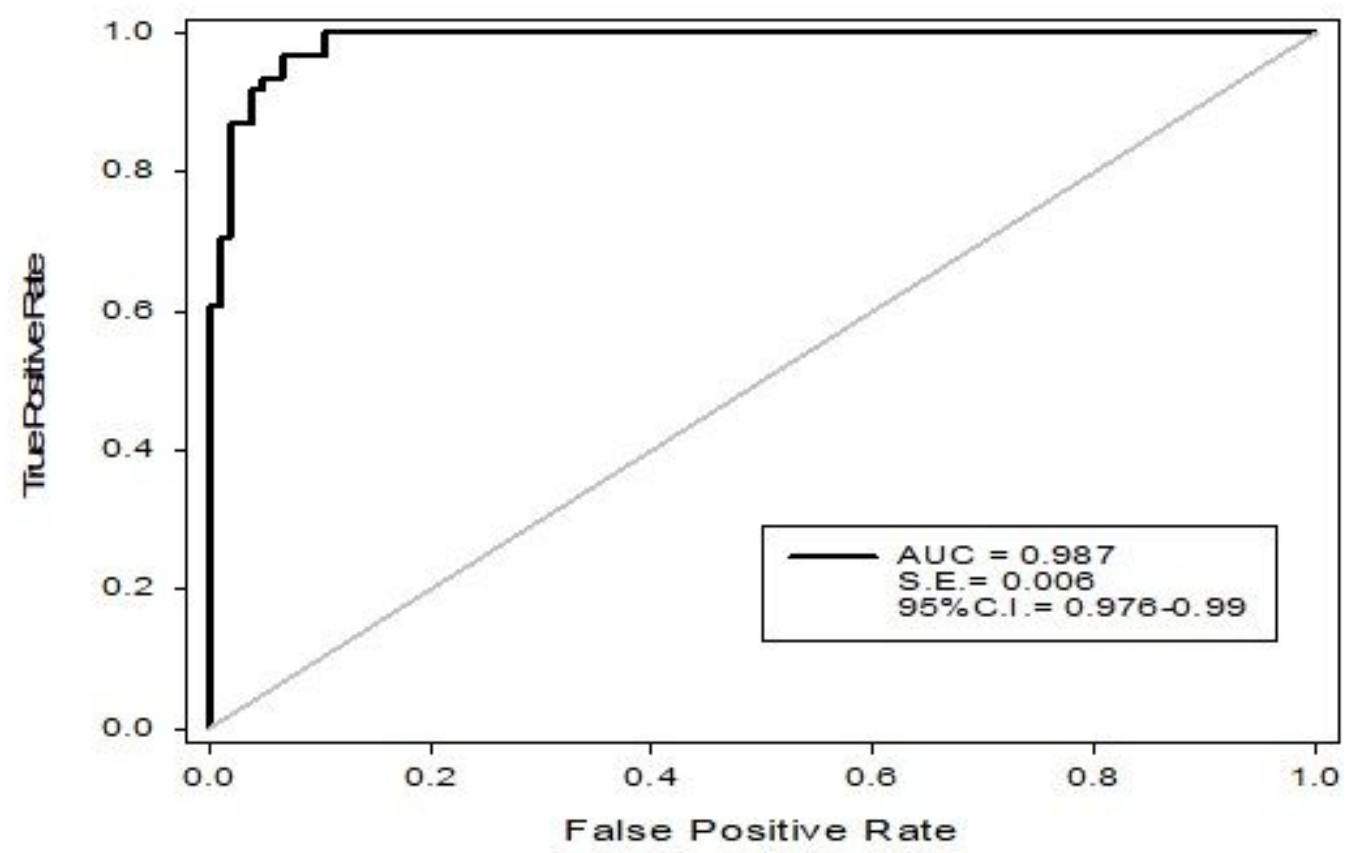

Figure 2 
ROC curve analysis of IncRNA CTBP1-AS in PCOS cases and healthy controls. 